${ }^{1}$ Clinical Effectiveness Committee, College of Emergency Medicine, London, UK

${ }^{2}$ Clinical Standards Department, Clinical Effectiveness and Evaluation Unit, Royal College of Physicians, London, UK

Correspondence to Dr Jay Banerjee, Emergency Department, University Hospitals of Leicester NHS Trust, Leicester Royal Infirmary, Infirmary Square, Leicester LE1 5WW, UK:

jb234@le.ac.uk

Accepted 6 October 2011

\title{
The National Falls and Bone Health Audit: implications for UK emergency care
}

\author{
Jay Banerjee, ${ }^{1}$ Jonathan Benger, ${ }^{1}$ Jonathan Treml, ${ }^{2}$ Finbarr C Martin, ${ }^{2}$ Rob Grant, ${ }^{2}$ \\ Derek Lowe, ${ }^{2}$ Jonathan Potter, ${ }^{2}$ Janet Husk ${ }^{2}$
}

\begin{abstract}
Introduction The National Clinical Audit of Falls and Bone Health, coordinated by the Royal College of Physicians, assesses progress in implementing integrated falls services across the UK against national standards and enables benchmarking between service providers. Nationally, falls are a leading contributor towards mortality and morbidity in older people and account for 700000 visits to emergency departments and 4 million annual bed days in England alone.

Methods Two rounds of national organisational audit in 2005 and 2008 and one national clinical audit in 2006 were carried out based on indicators developed by a multidisciplinary group.

Results These showed that management of falls and bone health in older people remains suboptimal in emergency departments and minor injury units and opportunities are being missed in carrying out evidencebased risk assessment and management.

Conclusions Older people attending emergency departments in the UK following a fall are receiving a poor deal. There is an urgent need to ensure more effective assessment and management to prevent further falls and fractures.
\end{abstract}

\section{INTRODUCTION}

Each year, over 700000 older people in the UK attend emergency departments (EDs) after a fall and many more attend minor injury units (MIUs), or call for ambulance assistance. Injurious falls, including over 60000 hip fractures annually, are the leading cause of accident-related mortality in older people. The National Service Framework for Older People ${ }^{1}$ emphasises that "preventing falls in older people depends on identifying those most at risk of falling and coordinating appropriate preventative action. Older people who attend accident and emergency departments having fallen should, with their consent, be referred to a specialist falls service."

The National Audit of Falls and Bone Health in the UK, is commissioned by the Healthcare Quality Improvement Partnership (HOIP, formerly Healthcare Commission), and is conducted by the Clinical Effectiveness and Evaluation Unit (CEEU) of the Royal College of Physicians, London. It is facilitated by a multidisciplinary steering committee representing the many different stakeholders involved in the care of older people after falls. The CEEU conducted an organisational audit in 2005 and then a patient-level clinical audit in 2006 before reauditing changes in the organisation of care in 2008. The objectives of the national audit are to assess progress across the UK in the implementation of integrated falls services against national standards and to enable benchmarked comparisons of the organisations and provision of falls and bone health services. This paper describes findings from this national audit that are relevant to EDs and MIUs.

\section{METHODS}

Indicators of the structure and process of highquality care were developed by a multidisciplinary steering group representing professional and patient organisations relevant to falls and bone health. The original brief was to audit the extent to which Trusts had met the requirements set out in the National Service Framework for Older People, ${ }^{1}$ and the group derived audit questions to match these and other standards and guidelines. ${ }^{2-5}$

The organisational audit of November/December 2005 covered England only and all eligible acute Trusts participated. The organisational audit of November/December 2008 recruited 95\% of eligible healthcare Trusts in England, Wales and Northern Ireland, and involved the acute hospital sector, primary care, combined health and social care organisations, and mental care trusts. Direct comparison between 2005 and 2008 is difficult because in 2005 acute Trusts provided overview information across the local falls service as a whole, whereas 2008 data were obtained separately from commissioning trusts, community, acute and mental healthcare providers about what specific services they themselves provided (structure indicators).

The clinical audit of October/November 2006 recruited acute hospitals in England, Wales, Northern Ireland and the Channel Islands, with 91\% submitting data on process indicators for individual patients. The audit covered two groups of patients aged $\geq 65$ years and presenting to the ED or MIU, those with a hip fracture and those with other fragility fractures (wrist, humeral, pelvic or vertebral). The audit asked for data on 20 consecutive hip fracture and 40 consecutive other fragility fracture cases, using a retrospective review of case notes. Data were submitted to a secure internet site with no transmission of personally identifiable information.

Organisational data were also entered into webbased data collection tools. Audit data were exported to the CEEU for cleaning, analysis and reporting. All audits were piloted for data proforma and the web tool.

\section{RESULTS}

Results from the two organisational audits of services for older people who fall and attend EDs are shown in table 1 . In 2005 , only $29 \%$ of acute Trusts 
Table 1 Results from the 2005 and 2008 organisational audits of emergency departments

2008 Audit question
Are older people who fall and
routtend A\&E departments or MIUs
roly screened for risk of future falls?
Is (routine) screening performed on site
in A\&E?
Is this available 7 days a week?
Within A\&E/MIUs are there systems for
providing onward direct referral for falls

providing onward direct referral for falls

and bone health assessments/treatment?

Are older people who attend A\&E/MIUs after a fall routinely assessed for osteoporosis risk?

Between September 2007 and August 2008 have there been any local audits performed to assess any aspects of the falls and bone health service?

Has an audit been performed on the screening of all older people attending A\&E for falls and osteoporosis risk?

$-$

Is there a local coordinated, integrated, multiprofessional and multiagency falls service?

$-$

Do you have a falls service coordinator(s)?

Do you have a fracture liaison nurse (s) or similar designated person(s)?

\section{Audit result \\ 2005 Audit question}

2005 Audit result

For those with A\&E or MIU:

Acute: $50 \%$ (92/183)

PCOs: $55 \%(53 / 96)$

HSCTs: $30 \%(3 / 10)$

Acute: $88 \%$ (81/92)

PCOs: $81 \%(43 / 53)$

HSCTs: $67 \%(2 / 3)$

Acute: $80 \%$ (65/81)

PCOs: $84 \%(36 / 43)$

HSCTs: $100 \%(2 / 2)$

For those with A\&E or MIU:

Acute: 75\% (138/183)

PCOs: $80 \%(77 / 96)$

HSCTs: $70 \%(7 / 10)$

For sites with A\&E or MIU:

Acute: $15 \%$ (28/183)

PCOs: $29 \%(28 / 96)$

HSCTs: $0 \%(0 / 10)$

Acute: 91\% (167/183)

PC0s: $67 \%$ (106/159)

$-$

$-$

HSCTs: $90 \%(9 / 10)$

Acute: $28 \%$ (46/167)

PCOs: NA

HSCTs: $11 \%(1 / 9)$

$-$

$-$

Acute: $70 \%$ (128/183)

PCOs: $75 \%$ (120/159)

HSCTs: $50 \%(5 / 10)$

$-$

Acute: $31 \%(55 / 175)$

PCOs $71 \%(111 / 157)$

HSCTs: $40 \%(4 / 10)$

Acute: $29 \%(51 / 175)$

PCOs $15 \%(24 / 157)$

HSCTs: $60 \%(6 / 10)$
Are older people who attend hospital following a

$41 \%(61 / 149)$ fall assessed for osteoporosis risk?

Is there a regular audit programme to assess

$62 \%(92 / 149)$ some aspects of the falls service?

$29 \%(44 / 150)$

Is this a $24 \mathrm{~h}$ service? $14 \%(6 / 44)$

Is there a coordinated multiprofessional specialist falls

$74 \%(111 / 151)$ service?

$44 \%(67 / 151)$

Has the specialist falls service agreed protocols for the care of older people with osteoporotic hip fracture with the A\&E department[s]?

Which of the following professionals have within their job description/job plan a commitment to the specialist falls service: Falls coordinator?

Is there a fracture liaison nurse or similar designated person who performs a falls and osteoporosis assessment on older people that have a fragility fracture? by a member of the specialist falls service?

Acute, acute hospital sector; MIU, minor injury unit; PCO, primary care organisation; HSCT, health and social care trusts.

used a member of a specialist falls service to assess such patients, and only $14 \%$ of these had a $24 \mathrm{~h}$ service. This, despite $74 \%$ of Trusts claiming they had a coordinated multiprofessional specialist falls service in their ED for the care of older people with osteoporotic fractures. Services were available to assess osteoporosis risk after falling in $41 \%$ of Trusts. In $2005,54 \%$ of services had a falls coordinator and $34 \%$ had a fracture liaison nurse.

The 2008 audit asked about services provided by acute hospitals, primary care, combined health and social care organisations, and mental care providers. Half $(51 \%, 148 / 289)$ of those with EDs or MIUs routinely screened older people after falls for risk of future falls. For commissioning providers (primary care, health and social care) with written commissioning strategies for falls prevention, $59 \%$ (43/73) routinely screened for future risk, compared with $39 \%$ (13/33) without written strategies. Routine screening was mostly done on site and available 7 days a week. Systems allowing staff to arrange direct referral for further assessment and treatment were available in $77 \%$ of providers with an ED or MIU (222/289). Only $19 \%(56 / 289)$ of providers with an ED/MIU routinely assessed older people for risk of osteoporosis after a fall. Among acute trusts and combined health and social care trusts, 91\% (176/193) had audited the quality of the falls and bone health service in the previous 12 months but only $27 \%$ of these (47/176) had audited on the screening of older patients in A\&E for falls and osteoporosis risk. In acute Trusts, 29\% (51/175) had a fracture liaison nurse and $31 \%(55 / 175)$ had a falls coordinator.

The 2006 clinical audit of patients presenting to emergency care with fractures after a fall gave results for separate aspects of multifactorial falls risk assessment (table 2). Often, considerably fewer than half the relevant number of patients with non-hip fragility fracture were being assessed: medication review $31 \%$, cardiovascular examination $40 \%$, vision $10 \%$, continence $21 \%$, mobility and balance $28 \%$. Only $22 \%$ were referred for exercise training to reduce falls and only $20 \%$ were receiving appropriate treatment by 12 weeks for osteoporosis. Whereas almost all (99.8\%) of patients with hip fracture were admitted to hospital, $66 \%(3700 / 5642)$ of patients with a non-hip fragility fracture were not admitted.

\section{DISCUSSION}

This is the most comprehensive audit cycle of UK falls and bone healthcare ever conducted and provides as true to life a picture of 
Table 2 Results from the 2006 clinical audit in relation to secondary prevention intervention within 12 weeks of falling

\begin{tabular}{|c|c|c|}
\hline Question & Non-hips (5642) & Hips (3184) \\
\hline Was there evidence of a medication review? & $31 \%(1773 / 5642)$ & $52 \%(1654 / 3184)$ \\
\hline Performance of a cardiovascular examination? & $40 \%(2240 / 5642)$ & $89 \%(2827 / 3184)$ \\
\hline $\begin{array}{l}\text { Did the patient have an assessment for visual } \\
\text { impairment? }\end{array}$ & $10 \%(573 / 5642)$ & $19 \%(595 / 3184)$ \\
\hline $\begin{array}{l}\text { Did the patient have an assessment of urinary } \\
\text { function including continence status? }\end{array}$ & $21 \%(1187 / 5642)$ & $63 \%(2009 / 3184)$ \\
\hline $\begin{array}{l}\text { Do the clinical records indicate that a gait, } \\
\text { balance and mobility assessment was performed? }\end{array}$ & $28 \%(1421 / 5086)$ & $68 \%(2018 / 2952)$ \\
\hline Has patient attended any form of exercise? & $22 \%(1108 / 4933)$ & $44 \%(1224 / 2764)$ \\
\hline $\begin{array}{l}\text { Was patient prescribed a bisphosphonate or other } \\
\text { appropriate treatment for osteoporosis? }\end{array}$ & $20 \%(1038 / 5311)$ & $43 \%(1301 / 3030)$ \\
\hline
\end{tabular}

actual clinical practice as is possible with large-scale audit. It demonstrates quite clearly that the management of falls and bone health in older people is suboptimal. This is especially important given the nature and size of the problem and future projections within an ageing population. Given that emergency care departments are often the first port of call for many older fallers, the relevance of the roles played by clinicians at this interface between secondary and primary care and the need for surveillance, assessment and management cannot be overstated.

Opportunities to prevent recurrent falls and fractures are being missed. Services with falls coordinators and fracture liaison nurses probably have better case-finding systems in place to identify high-risk fallers than services that do not. ${ }^{6}$ Assessment rates for secondary prevention are so low that many clinical services clearly do not adhere to NICE guidelines on preventing falls and fractures. Half of the patients with hip fractures have previously had a fragility fracture of another bone, $^{7}$ and hence there are missed opportunities to reduce the incidence of subsequent hip fractures in this group by using osteoporosis treatment and falls risk reduction. The clinical audit indicated that two-thirds of patients presenting with a non-hip fragility fracture were not admitted to hospital. This means that the majority of high-risk patients miss the best or only opportunity for their falls and fracture risk to be identified in the majority of hospitals. Local strategies are needed to enable the case-finding opportunity at the point of presentation to be coordinated with subsequent primary and community healthcare responses. In addition, every primary care organisation needs a strategy to for case finding other patients at high risk.

An audit ${ }^{8}$ showed that in managing older patients after a fall, the ED focused on injuries sustained but little effort was made to establish and manage risk factors to prevent recurrent falls. Furthermore, falls are a geriatrics syndrome, which indicates that the individual is also at higher risk of adverse outcomes. The DEED II trial ${ }^{9}$ and the PROFET study ${ }^{10}$ demonstrated that comprehensive geriatric assessment and multidisciplinary intervention can improve health outcomes of older people at risk of deteriorating health and admission to hospital.

More research is needed, however, into the management of older people presenting with falls in EDs and into the reasons for non-concordance with evidence-based practice which are multifactorial. The acute care setting, targets and consequent influence on patient investigation and shared decision-making may alter the focus on different aspects of patient management, resulting in less time being spent on risk assessment for future falls or fragility fractures than managing the immediate consequent injuries. Attitudes towards, and knowledge and uptake of, evidence-based management may also affect management of these patients. Lack of knowledge on older peoples' issues, ageism, sociocultural and communication barriers and health beliefs of patients may all influence elements of care delivery.

In summary, older people attending EDs in the UK after a fall are 'receiving a poor deal'. There is an urgent need to ensure more effective assessment and management to prevent further falls and fractures. Ideally, all elderly patients attending EDs should be asked about their history of falls in the previous 12 months and assessed for mobility and balance problems. Patients identified as being at risk of falling should receive assessment for fracture risk and should be referred for appropriate falls and/or osteoporosis assessment and treatment.

\section{Competing interests None.}

Contributors All authors contributed to developing the manuscript.

Provenance and peer review Not commissioned; externally peer reviewed.

\section{REFERENCES}

1. Department of Health. National Service Framework for Older People. 2001, Chapter 6 "Falls". http://www.dh.gov.uk/prod_consum_dh/groups/dh_digitalassets/ @dh/@en/documents/digitalasset/dh_4071283.pdf (accessed 24 Mar 2011).

2. National Institute for Health and Clinical Excellence. Clinical Guideline (CG) 21 (2004). Falls: the assessment and prevention of falls in older people. http://www. nice.org.uk/nicemedia/live/10956/29585/29585.pdf (accessed 24 Mar 2011).

3. National Institute for Health and Clinical Excellence. Technology Appraisal (TA) 161 (2008). Alendronate, Etidronate, Risedronate, Raloxifene, Strontium ranelate and Teriparatide for the Secondary Prevention of Osteoporotic Fragility Fractures in Post Menopausal Women. http://guidance.nice.org.uk/TA161 (accessed 24 Mar 2011).

4. British Orthopaedic Association and British Geriatric Society. The Care of Patients with Fragility Fracture. 2007. http://www.fractures.com/pdf/BOA-BGS-BlueBook.pdf (accessed 24 Mar 2011).

5. National Patient Safety Agency. Slips, Trips and Falls in Hospitals. 2007. http:// www.nrls.npsa.nhs.uk/resources/?entryid45=59821 (accessed 24 Mar 2011).

6. Department of Health. Falls and Fractures: Effective Interventions in Health and Social Care. 2010. http://www.dh.gov.uk/prod_consum_dh/groups/dh_digitalassets/ @dh/@en/@pg/documents/digitalasset/dh__109122.pdf (accessed 24 Mar 2011).

7. Klotzbuecher CM, Ross P, Landsmann P, et al. Patients with prior fractures have an increased risk of future fractures: a summary of the literature and statistical synthesis. J Bone Miner Res 2005;15:721-39.

8. Kalula SZ, De Villiers L, Ross K, et al. Management of older patients presenting after a fall - an accident and emergency department audit. S Afr Med J 2006;96:718-21.

9. Caplan GA, Williams AJ, Daly B, et al. A randomized, controlled trial of comprehensive geriatric assessment and multidisciplinary intervention after discharge of elderly from the emergency department-the DEED II study. J Am Geriatr Soc 2004;52:1417-23.

10. Close J, Ellis M, Hooper R, et al. Prevention of falls in the elderly trial (PROFET): a randomised controlled trial. Lancet 1999:353:93-7. 


\section{EM]}

\section{The National Falls and Bone Health Audit: implications for UK emergency care}

Jay Banerjee, Jonathan Benger, Jonathan Treml, et al.

Emerg Med J published online November 1, 2011

doi: 10.1136/emermed-2011-200501

Updated information and services can be found at:

http://emj.bmj.com/content/early/2011/10/31/emermed-2011-200501.full.html

\section{These include:}

References This article cites 4 articles http://emj.bmj.com/content/early/2011/10/31/emermed-2011-200501.full.html\#ref-list-1

$\mathbf{P}<\mathbf{P} \quad$ Published online November 1, 2011 in advance of the print journal.

Email alerting

Receive free email alerts when new articles cite this article. Sign up in service the box at the top right corner of the online article.

Notes

Advance online articles have been peer reviewed, accepted for publication, edited and typeset, but have not not yet appeared in the paper journal. Advance online articles are citable and establish publication priority; they are indexed by PubMed from initial publication. Citations to Advance online articles must include the digital object identifier (DOIs) and date of initial publication.

To request permissions go to:

http://group.bmj.com/group/rights-licensing/permissions

To order reprints go to:

http://journals.bmj.com/cgi/reprintform

To subscribe to BMJ go to:

http://group.bmj.com/subscribe/ 